\title{
Upregulated microRNA-143 inhibits cell proliferation in human nasopharyngeal carcinoma
}

\author{
BENFU HE ${ }^{1 *}$, ZHE XU $^{2 *}$, JINZHANG CHEN ${ }^{3}$, DAYONG ZHENG ${ }^{3},{\text { AIMIN } \mathrm{LI}^{4} \text { and LUO-SHENG ZHANG }}^{5}$ \\ ${ }^{1}$ Department of Oncology, PLA421 Hospital, Guangzhou, Guangdong 510318; \\ ${ }^{2}$ Department of Pediatric Surgery, First Affiliated Hospital of Sun Yat-sen University, Guangzhou, Guangdong 510080; \\ ${ }^{3}$ Department of Oncology, Nanfang Hospital, Southern Medical University, Guangzhou, Guangdong 510515; \\ ${ }^{4}$ Department of Oncology, Integrated Chinese and Western Medicine Hospital, Southern Medical University, \\ Guangzhou, Guangdong 510310; ${ }^{5}$ Department of Oncology, PLA458 Hospital, Guangzhou, Guangdong 510080, P.R. China
}

Received July 13, 2015; Accepted October 18, 2016

DOI: $10.3892 / \mathrm{ol} .2016 .5363$

\begin{abstract}
The aim of the present study was to investigate the possible functions and mechanism of microRNA (miR)-143 in cell proliferation of human nasopharyngeal carcinoma (NPC). The expression of miR-143 in NPC cells and tissues was investigated using reverse transcription-quantitative polymerase chain reaction. Cell viability assay, colony formation assay and flow cytometry were used to examine the cell proliferative ability and tumorigenicity. The expression levels of p21 ${ }^{\text {Cip1 }}, \mathrm{p} 27^{\mathrm{Kip} 1}$, cyclin $\mathrm{D} 1$, phosphorylated (p)-retinoblastoma protein $(\mathrm{Rb}), \mathrm{Rb}$ and cyclin-dependent kinase (CDK) 6 were determined by western blotting. Luciferase assay was used to confirm whether CDK6 was a direct target of miR-143. miR-143 was downregulated in NPC cell lines and tissues. Overexpression of miR-143 in NPC CNE1 cells inhibited proliferation, tumorigenicity and cell cycle progression. Additionally, ectopic expression of miR-143 downregulated cyclin D1 and p-Rb expression, and upregulated p21 $1^{\text {Cip } 1}$ and $\mathrm{p} 27^{\mathrm{Kip} 1}$ expression, which subsequently inhibited NPC cell proliferation. It was also observed that CDK6 was a direct target of miR-143, which downregulated CDK6 expression. CDK6 suppression by miR-143 was associated with dysregulated expression of $\mathrm{p} 21^{\mathrm{Cip} 1}, \mathrm{p} 27^{\mathrm{Kip} 1}$, cyclin D1 and $\mathrm{p}-\mathrm{Rb}$, thereby serving an essential role in NPC cell growth. Our findings suggest that miR-143 inhibits proliferation by targeting CDK6, and may aid to identify new targets for anti-oncomiRs.
\end{abstract}

\section{Introduction}

Nasopharyngeal carcinoma (NPC) is the most common malignant tumor in South China (1). The majority of

Correspondence to: Dr Luo-Sheng Zhang, Department of Oncology, PLA458 Hospital, 801 Dong-Feng Road East, Guangzhou, Guangdong 510080, P.R. China

E-mail: lawysun@163.com

${ }^{*}$ Contributed equally

Key words: miR-143, CDK6, NPC, proliferation studies have reported that the etiologic factors of NPC are associated with genetic susceptibility, Epstein-Barr virus infection and other environmental factors $(2,3)$. However, the exact genetic changes, such as in microRNAs (miRNAs or miRs), that influence NPC progression remain largely unknown.

miRNAs are small non-coding RNAs of 20-22 nucleotides in length. miRNAs are recognized as novel markers that are important in multiple biological functions of various human cancers, including cell growth, migration, differentiation, apoptosis, metastasis and angiogenesis (4-6). miRNAs negatively regulate gene expression levels post-transcriptionally by targeting the 3'-untranslated region (UTR) of messenger RNAs (mRNAs) in a sequence-specific manner $(7,8)$. Based on previous studies on the regulation of miRNAs in the biological progression of multiple cancers, miRNAs are presently considered as potential novel targets for anti-cancer therapies $(5,9,10)$.

miR-143 is located on chromosome 5 q32, and its expression is decreased in a variety of tumors. As a tumor-suppressor gene, miR143 expression is negatively correlated with malignant processes and patient's survival, since it inhibits cell proliferation, migration and metastasis (11-16). However, the mechanism that explains the regulation of cell proliferation in NPC by miR-143 remains unknown.

The present study noticed low miR-143 expression in NPC specimens and NPC cell lines. These results suggest that miR-143 affects tumor proliferation, invasion and metastasis, and that miR-143 is associated with NPC development. It was also observed that miR-143 targeted the oncogene cyclin-dependent kinase (CDK) 6 directly, downregulating it, and that $\mathrm{CDK} 6$ is essential for the regulation of miR-143 in NPC cells in vitro. Our study demonstrates that miR-143 inhibits cell proliferation and tumorigenicity in NPC by targeting CDK6 and suppressing its expression.

\section{Materials and methods}

NPC cell lines and treatments. The NPC cell lines CNE1, CNE2, 6-10B, 5-8F and HONE1 were obtained from the 
American Type Culture Collection (Manassas, VA, USA) and cultured in Dulbecco's modified Eagle's medium (Invitrogen; Thermo Fisher Scientific, Inc., Waltham, MA, USA) supplemented with $10 \%$ fetal bovine serum (HyClone; GE Healthcare Life Sciences, Logan, UT, USA) and $1 \%$ penicillin/streptomycin. All cells were maintained in a humidified atmosphere at $37^{\circ} \mathrm{C}$ with $5 \% \mathrm{CO}_{2}$. NP69 cells (used as control) were kindly offered by Professor Libing Song (State Key Laboratory of Oncology in Southern China, Sun Yat-sen University, Guangzhou, China and Department of Experimental Research, Sun Yat-sen University Cancer Center, Guangzhou, China). The miR-143 mimic, miR-143 mimic mutant (miR-143-mut), miR-143 inhibitor and negative control (NC) miRNA were purchased from Guangzhou RiboBio Co., Ltd. (Guangzhou, China). For silencing CDK6 expression, a specific small interfering siRNA (siRNA) was synthesized and purified by Guangzhou RiboBio Co., Ltd. Transfection of oligonucleotides and siRNA was performed using Lipofectamine 2000 reagent (Invitrogen; Thermo Fisher Scientific, Inc.) according to the manufacturer's protocol.

NPC specimens. Eight pairs of snap-frozen NPC and adjacent tissue were collected from patients undergoing curative resection and diagnosed histopathologically at PLA421 Hospital (Guangzhou, China) from 2006 to 2010. The present study was conducted on eight pairs of NPC tumors and matched normal tissue from adjacent regions, which were diagnosed histopathologically by experienced pathologists. All samples were immediately frozen and stored in liquid nitrogen until further analysis. All samples were obtained with informed consent and approved by the Institutional Research Ethics Committee of PLA421 Hospital.

$R N A$ extraction and reverse transcription-quantitative polymerase chain reaction ( $R T-q P C R)$. Total RNA was extracted from the cultured cells using TRIzol (Invitrogen; Thermo Fisher Scientific, Inc.) according to the manufacturer's protocol. RT-qPCR was performed using SYBR Green I Nucleic Acid Gel Stain (Invitrogen; Thermo Fisher Scientific, Inc.) in an ABI 7500 Real-Time PCR System (Applied Biosystems; Thermo Fisher Scientific, Inc.). Gene expression data were normalized to the geometric mean of the $\beta$-actin housekeeping gene to control for variability in the expression levels, and calculated as $2^{-[(\mathrm{Cq} \text { of gene)-(Cq of }}$ $\beta$-actin)], where Cq represents the quantification cycle for each transcript. The primers selected were as follows: $\mathrm{p} 21^{\mathrm{Cip} 1}$ forward 5'-CGATGCCAACCTCCTCAACGA-3', p21 $1^{\text {Cip1 }}$ reverse 5'-TCGCAGACCTCCAGCATCCA-3', p27 ${ }^{\mathrm{Kip} 1}$ forward 5'-TGCAACCGACGATTCTTCTACTCAA-3', p27 ${ }^{\mathrm{Kip} 1}$ reverse 5'-CAAGCAGTGATGTATCTGATAAAC AAGGA-3', cyclin D1 forward 5'-AACTACCTGGACCGC TTCCT-3', cyclin D1 reverse 5'-CCACTTGAGCTTGTT CACCA-3', $\beta$-actin forward 5'-TGGCACCCAGCACAA TGAA-3' and $\beta$-actin reverse 5'-CTAAGTCATAGTCCG CCTAGAAGCA-3'.

Western blotting. Cell lysates were extracted using radioim-

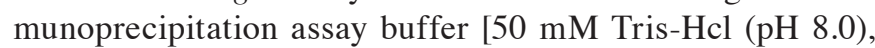
$150 \mathrm{mM} \mathrm{NaCl}, 1 \%$ Triton X-100 and protease inhibitor cocktail;
Sigma-Aldrich; Merck Millipore, Darmstadt, Germany]. Equal amounts of protein $(40 \mu \mathrm{l})$ were separated by $12 \%$ SDS-PAGE and transferred onto polyvinylidene fluoride membranes. The membranes were blocked using 5\% non-fat milk, and probed with antibodies against cyclin D1 (1:1,000; cat. no. ab134175), p21 ${ }^{\text {Cipl }}$ (1:1,000; cat. no. ab109520), p2 $7^{\text {Kip1 }}$ $(1: 1,000$; cat. no. ab32034), retinoblastoma protein $(\mathrm{Rb})$ (1:1,000; cat. no. ab181616), phosphorylated (p)-Rb (1:1,000; cat. no. ab47763) and CDK6 (1:1,000; cat. no. ab124821; all Abcam, Cambridge, UK) for $2 \mathrm{~h}$ at room temperature. After washing three times with TBST for $5 \mathrm{~min}$ each, the membranes were incubated with the secondary antibody $(1: 5,000$; cat. nos. A9169 and A9044; Sigma-Aldrich; Merck Millipore) for $1 \mathrm{~h}$ at room temperature. After washing the membranes with TBST three times for $5 \mathrm{~min}$ each, the membranes were stripped and reprobed with anti- $\beta$-actin mouse monoclonal antibody (1:1,500; cat. no. A5441; Sigma-Aldrich; Merck Millipore) as a loading control. The Immobilon Western Chemiluminescent HRP Substrate (Merck Millipore) was used to visualize the bands.

MTT assay. MTT assay was performed to quantify NPC cell viability. Cells were stained with $100 \mu \mathrm{l}$ sterile MTT $(0.5 \mathrm{mg} / \mathrm{ml}$; Sigma-Aldrich; Merck Millipore) for $4 \mathrm{~h}$ at $37^{\circ} \mathrm{C}$. The culture medium was then removed and formazan crystals in the cells were solubilized using dimethyl sulfoxide (Sigma-Aldrich; Merck Millipore) with plate incubation for $30 \mathrm{~min}$. Cells were incubated for $36 \mathrm{~h}$ at $37^{\circ} \mathrm{C}$ in a humidified $5 \% \mathrm{CO}_{2}$ atmosphere. Absorbance was measured at a $490-\mathrm{nm}$ wavelength. The experiments were performed independently in triplicate.

Colony formation assay. Cells were seeded on a 6-well plate $\left(1.0 \times 10^{3}\right.$ cells/well) and cultured for 10 days. Colonies were fixed for $5 \mathrm{~min}$ with $10 \%$ formaldehyde and stained with $1.0 \%$ crystal violet for $1 \mathrm{~min}$. The experiments were performed independently in triplicate.

Flow cytometry. Cells were harvested by trypsinization, washed in ice-cold PBS and fixed in 75\% ice-cold ethanol. Cells were then treated with bovine pancreatic RNAase $\left(2 \mu \mathrm{g} / \mathrm{ml}\right.$; Sigma-Aldrich; Merck Millipore) at $37^{\circ} \mathrm{C}$ for $30 \mathrm{~min}$, followed by incubation with propidium iodide $(20 \mu \mathrm{g} / \mathrm{ml}$; Sigma-Aldrich; Merck Millipore) for $20 \mathrm{~min}$. Cell cycle analysis was determined using an LSR II flow cytometer (BD Biosciences, Franklin Lakes, NJ, USA) with FACSDiva 6.0 software (BD Biosciences).

Luciferase assay. The region of the human CDK6 3'-UTR containing miR-143 binding site was amplified by PCR from genomic DNA and cloned into the pGL3 vector (Promega Corporation, Madison, WI, USA) using Sac II and Pst I restriction enzymes. The primers used were as follows: CDK6 3'UTR upstream, 5'-TCCCCGCGGAAATGCAGC TGTTCTGAACTGG-3' and downstream, 3'-AACTGC AGA AATGCCCTAACGGCAAGAC-5'. The cycling conditions were as follows: Initial denaturation at $94^{\circ} \mathrm{C}$ for $5 \mathrm{~min}$; followed by 35 cycles of denaturation at $94^{\circ} \mathrm{C}$ for $15 \mathrm{sec}$, annealing at $60^{\circ} \mathrm{C}$ for $45 \mathrm{sec}$ and elongation at $72^{\circ} \mathrm{C}$ for $30 \mathrm{sec}$; and finally elongation at $72^{\circ} \mathrm{C}$ for $5 \mathrm{~min}$. Cells 
A

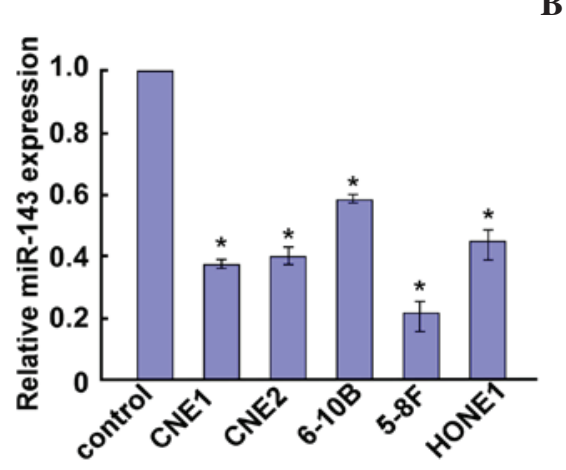

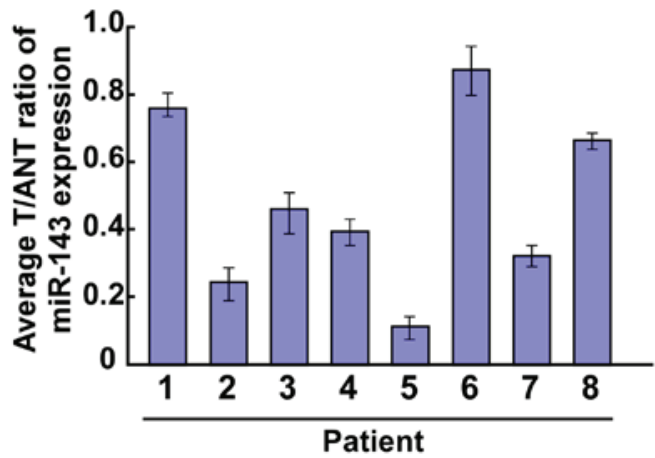

Figure 1. miR-143 is downregulated in nasopharyngeal carcinoma. (A) RT-qPCR analysis of miR-143 expression in CNE1, CNE2, 6-10B, 5-8F and NP69 (control) cells. (B) RT-qPCR analysis of miR-143 expression in eight paired cancerous tissues and their adjacent noncancerous tissues. Each bar represents the mean \pm standard deviation of three independent experiments. * $\mathrm{P}<0.05$. miRNA, microRNA; RT-qPCR, reverse transcription-quantitative polymerase chain reaction; T, tumor; ANT, adjacent non-tumor.

were seeded in triplicate in a 24-well plate and allowed to settle for $24 \mathrm{~h}$. pGL3-CDK6-luciferase plasmid (100 ng) was transfected into CNE1 cells using Lipofectamine 2000 reagent. Luciferase, and control signals were measured at $48 \mathrm{~h}$ after transfection using the Dual-Luciferase Reporter Assay System (Promega Corporation), according to the protocol provided by the manufacturer.

Statistical analysis. Statistical analyses were performed using SPSS 20.0 software (IBM SPSS, Armonk, NY, USA). The Student $t$-test was used to evaluate significant differences between two groups of data in all relevant experiments. All results are presented as means \pm standard deviation. $\mathrm{P}<0.05$ (two-tailed paired $t$-test) was considered to indicate a statistically significant difference.

\section{Results}

miR-143 is downregulated in NPC cell lines and clinical tissues. RT-qPCR revealed that miR-143 was markedly downregulated in all five NPC cell lines compared with the control cell line (NP69) (Fig. 1A). Furthermore, miR-143 was significantly downregulated in eight NPC tumor tissues compared with the control tissues (Fig. 1B). Taken together, these data demonstrate that miR-143 expression is decreased in NPC tissues and cell lines.

Ectopic miR-143 regulates NPC cell proliferation. To explore the biological function of miR-143 in NPC progression, miR-143 expression was determined by RT-qPCR in CNE1 cells transfected with miR-143 mimic and inhibitor (Fig. 2A). Cell viability was then measured by MTT assay, revealing that miR-143 overexpression decreased the CNE1 cell growth rate, while inhibiting miR-143 expression increased it (Fig. 2B). The colony formation assay demonstrated that miR-143 upregulation inhibited the colony formation capacity of CNE1 cells, while miR-143 downregulation promoted it (Fig. 2C). Flow cytometry revealed decreased miR-143 expression in the $\mathrm{S}$ phase compared with that observed in the control cells (Fig. 2D). Collectively, these results suggest that downregulation of miR-143 enhances NPC cell proliferation.
CDK6 is a direct target of miR-143 in NPC cells. miRNAs regulate mRNAs by targeting their 3'-UTRs. Thus, TargetScan (www.targetscan.org/), PicTar (http://pictar.mdc-berlin.de/) and miRanda (http://www.microrna.org/microrna/home.do) were used to predict the potential targets of miR-143 in humans. The analysis revealed a miR-143 binding site in the CDK6 mRNA 3'-UTR (Fig. 3A). As predicted, western blotting revealed that miR-143 downregulated CDK6 expression in CNE1 cells, and that miR-143 inhibition upregulated it (Fig. 3B). To confirm the direct regulation of CDK6 by miR-143, a pGL3-CDK6-3'-UTR-luciferase reporter vector containing the miR-143 binding site was constructed. The luciferase assay demonstrated that ectopic miR-143 expression decreased the luciferase activity, and that miR-143 downregulation increased the pGL3-CDK6-3'-UTR-luciferase reporter activity. By contrast, in our control experiment, mutant miR-143 had no effect on the luciferase expression driven by the pGL3-CDK6-3'-UTR-luciferase reporter vector (Fig. 3C). Collectively, these results suggest that miR-143 directly targets CDK6 in NPC cells.

Our results reveal that miR-143 may regulate NPC cell proliferation. Subsequently, its effects on the expression level of genes associated with the cell cycle and cell proliferation were evaluated. It was observed that the mRNA levels of $\mathrm{p} 21^{\text {Cip1 }}$ and p2 $7^{\text {Kip1 }}$ were significantly upregulated, while those of cyclin D1 were significantly downregulated (Fig. 3D). Furthermore, the protein expression levels of $\mathrm{p} 21^{\mathrm{Cip} 1}$ and $\mathrm{p} 27^{\mathrm{Kip} 1}$ were upregulated, while those of cyclin D1 were downregulated, and $\mathrm{p}-\mathrm{Rb}$ was decreased in miR-143-overexpressing cells compared with NC cells. By contrast, the expression levels of $\mathrm{p} 21^{\text {Cip1 }}$ and p2 $7^{\mathrm{Kip} 1}$ were downregulated, while cyclin D1 was upregulated and $\mathrm{Rb}$ phosphorylation was increased in cells transfected with miR-143 inhibitor (Fig. 3E). These results further confirm that miR-143 is important in NPC cell proliferation by regulating CDK6 and certain cell cycle-related regulators.

Clinical relevance of miR-143 downregulation and CDK6 expression in NPC. To examine the clinical association between miR-143 and CDK6, miR-143 levels and CDK6 expression were examined in eight fresh clinical NPC tissue samples. Statistical analysis demonstrated that miR-143 expression was inversely correlated with CDK6 ( $r=-0.63, \mathrm{P}=0.035$; Fig. 3F). 
A

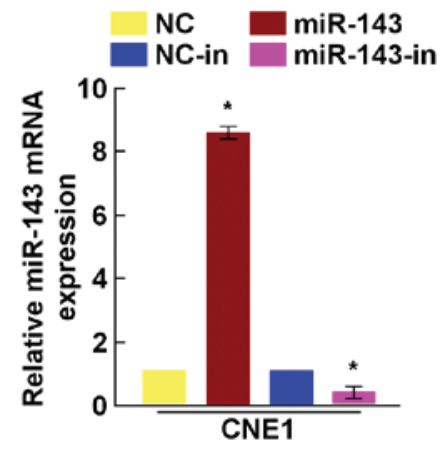

B

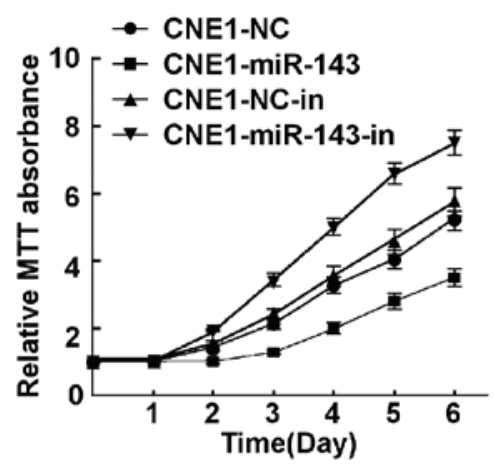

C
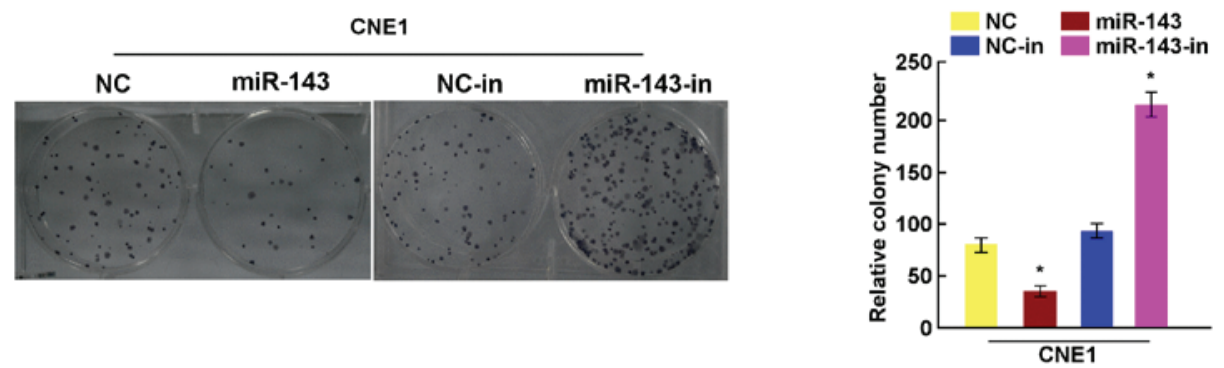

D

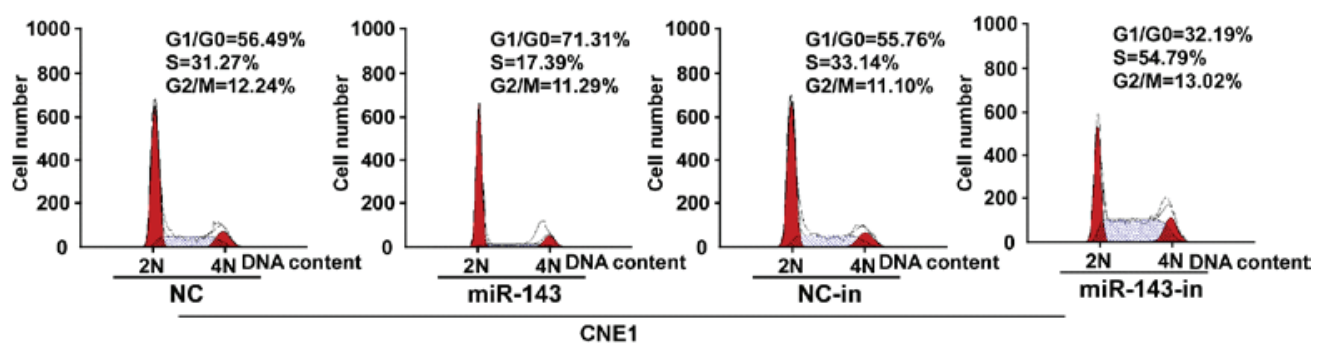

Figure 2. miR-143 affects nasopharyngeal carcinoma cell proliferation and tumorigenicity. (A) Reverse transcription-quantitative polymerase chain reaction determination of miR-143 expression level in CNE1 cells transfected with miR-143 mimic or inhibitor, or with negative control. (B) MTT assay analysis of the effect of miR-143 overexpression or downregulation on the relative CNE1 cell viability. (C) Colony formation assay analysis of CNE1 cells. (D) Flow cytometry analysis of the effect of miR-143 on cell cycle progression. Bars represent the mean \pm standard deviation of three independent experiments. "P<0.05. miRNA, microRNA; NC, negative control; in, inhibitor; mRNA, messenger RNA.

CDK6 suppression is essential for miR-143-mediated effects in NPC. As reported above, miR-143 targeting of CDK6 was closely correlated with cell proliferation. Therefore, endogenous CDK6 expression was suppressed for further investigation. Cell proliferation was analyzed using MTT and colony formation assays to further confirm the link between miR-143 and the suppression of CDK6 in NPC cells. CDK6 was downregulated in miR-143 inhibitor-transfected cells that contained CDK6 siRNA (Fig. 4A). The MTT and colony formation assays indicated that CDK6 suppression decreased the growth rate of NPC cells transfected with miR-143 inhibitor (Fig. 4B and C). These data confirmed that miR-143 inhibits NPC cell proliferation and tumorigenicity by downregulating CDK6 expression, and that CDK6 suppression is essential for the miR-143-mediated effects on NPC cell proliferation.

\section{Discussion}

The present study evaluated the function of miR-143 in NPC. In the current study, miR-143 was significantly downregulated in NPC cells and tumor tissues compared with control cells and adjacent regions tissues. Furthermore, ectopic miR-143 regulated
NPC cell proliferation in vitro. It was also demonstrated that CDK6 is a direct target of miR-143, and that it was downregulated through its 3'-UTR. Importantly, miR-143 decreased the expression of the cell cycle regulators cyclin D1 and CDK6, inhibited $\mathrm{Rb}$ phosphorylation, and increased the expression of $\mathrm{p} 21^{\mathrm{Cip} 1}$ and p27 $7^{\text {Kipl }}$. These results suggest that miR-143 may be important in inhibiting NPC carcinogenesis, progression and cell cycle.

Previous studies have shown that increasing the expression levels of the cell cycle inhibitors $\mathrm{p} 21^{\mathrm{Cipl}}$ and $\mathrm{p} 27^{\mathrm{Kipl}}$ and decreasing the expression levels of the cell cycle regulator cyclin D1 leads to G1/S arrest (17). CDK6 is an important cell cycle regulatory factor (18), and is a member of the cyclin D family of proteins, which are responsible for early G1 regulation. In the early phase of the cell cycle, G1 transition is mainly regulated by cyclin D1 complexed with CDK4 and/or CDK6 (19).

miRNA regulation of CDK6 has been reported elsewhere. For example, Wang et al observed that miR-320c inhibited the tumorous behavior of bladder cancer by targeting CDK6 (20). Furthermore, it has been reported that miR-145, miR-504 and miR-105 all directly target CDK6 and regulate endogenous CDK6 expression in cancer cells. Suppressing these miRNAs resulted in increased CDK6 and affected cell growth (21-23). 
A

$\begin{array}{cc}\begin{array}{c}\text { miR-143-mut } \\ \text { miR-143 }\end{array} & \text { 3'CUCGAUGUCACGAAGGGAAGU5' } \\ \text { 3'CUCGAUGUCACGAAGUAGAGU5' } \\ \text { CDK6-3'UTR } & 5^{\prime}{ }_{2548} \text { CACAGAAUGAAAGGGCAUCCUCAG }_{2570} 3^{\prime}\end{array}$

B

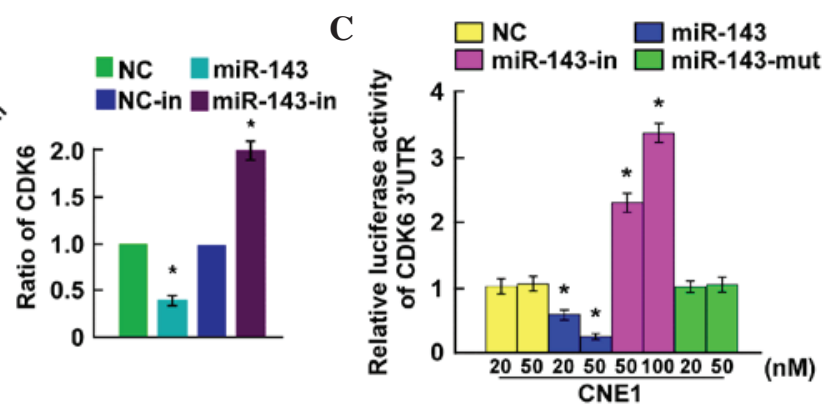

D

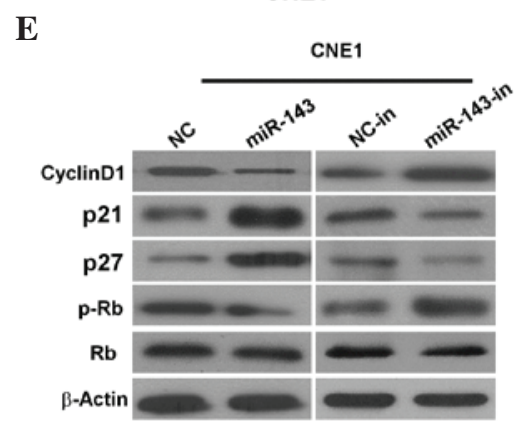

$\mathbf{F}$
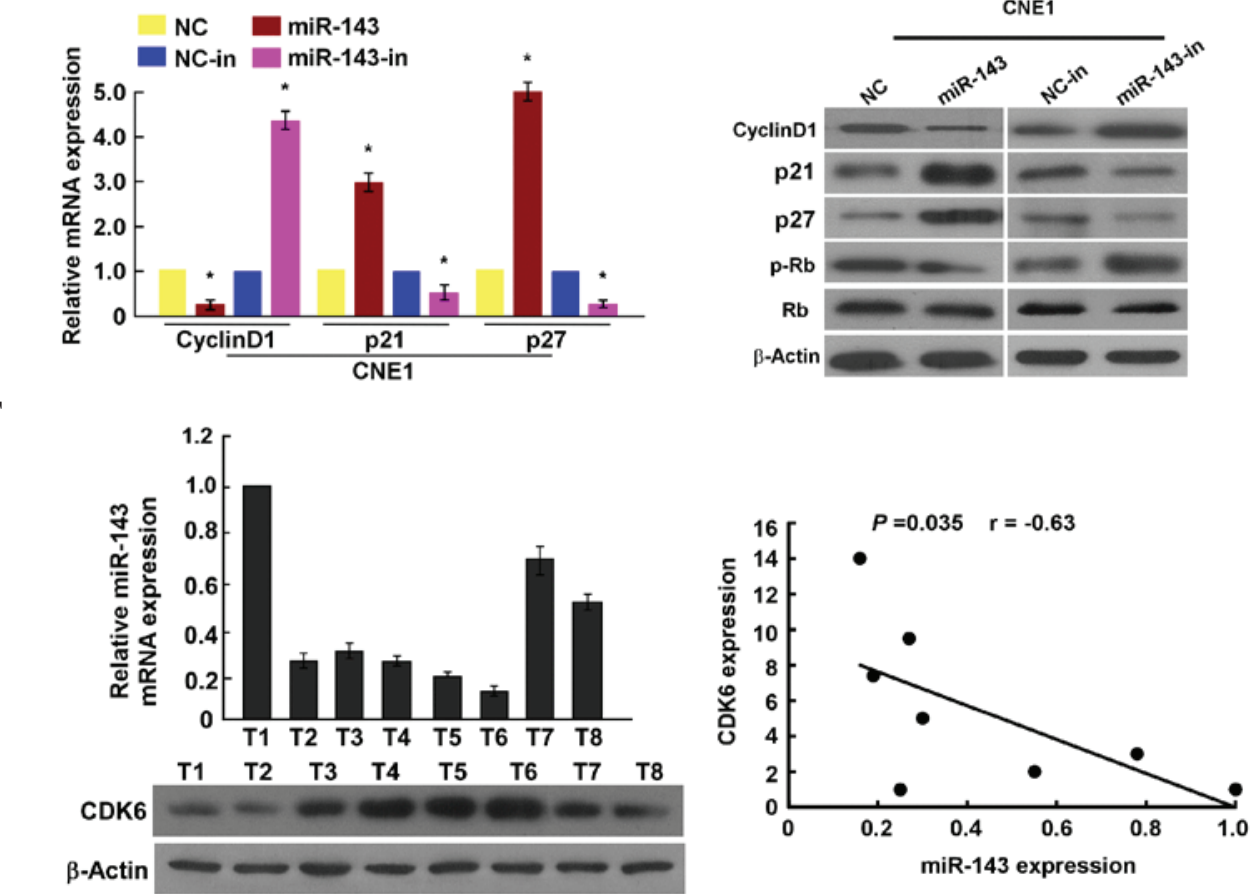

Figure 3. CDK6 is a direct target of miR-143. (A) Sequence alignment of miR-143, miR-143 mutant and putative CDK6 3'-UTR, and miR-143 binding sites. (B) Western blotting analysis of CDK6 expression levels in nasopharyngeal carcinoma cell lines overexpressing miR-143 or treated with miR-143 inhibitor compared with control cells. (C) CDK6 luciferase reporter activity in CNE1 cells transfected with miR-143 mimic, miR-143 mutant, miR-143 inhibitor or negative control. (D) RT-qPCR analysis of p21, p27 and cyclin D1_mRNA expression in CNE1 cells. (E) Western blot determination of p21, p27, cyclin D1, p-Rb and Rb expression in CNE1 cells. (F) RT-qPCR and western blot analysis of miR-143 and CDK6 expression, respectively. The bottom panel depicts the results of the statistical analysis of the correlation between miR-143 and CDK6 expression levels. Bars represent the mean \pm standard deviation of three independent experiments. " $\mathrm{P}<0.05$. miR, microRNA; CDK, cyclin-dependent kinase; UTR, untranslated region; NC, negative control; mut, mutant; in, inhibitor; mRNA, messenger RNA; Rb, retinoblastoma protein; p-, phosphoryulated; T, tumor; RT-qPCR, reverse transcription-quantitative polymerase chain reaction.
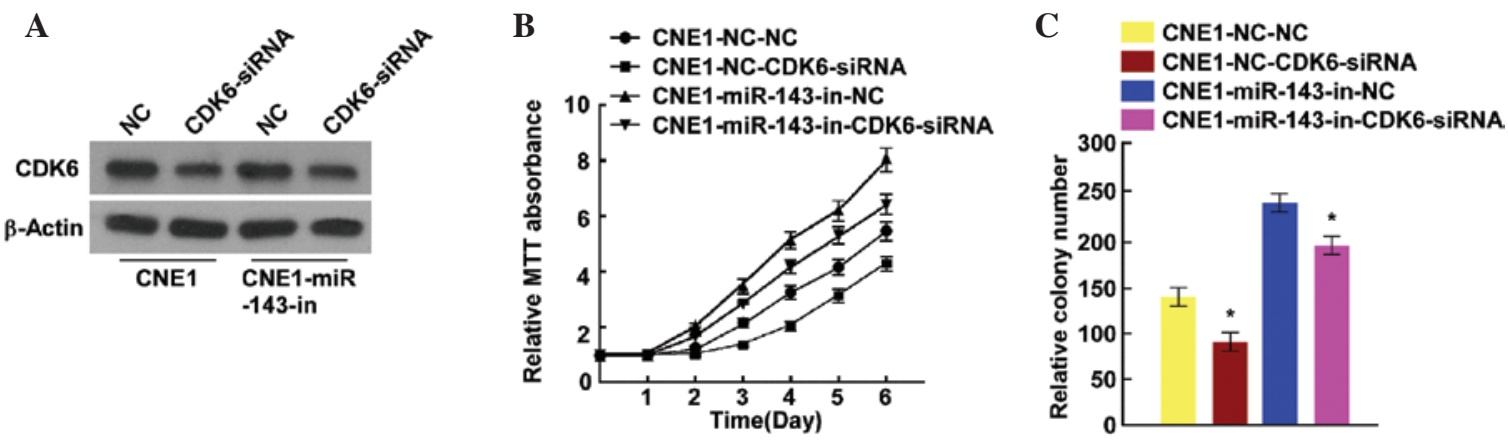

Figure 4. miR-143 enhances nasopharyngeal carcinoma cell proliferation by suppressing CDK6. (A) Western blotting determination of CDK6 expression levels in miR-143 inhibitor-transfected CNE1 cells transfected with CDK6 siRNA. (B) MTT assay of the relative cell viability of CDK6-silenced cells. (C) CNE1 cell colonies formed following treatment with CDK6-siRNA. Error bars represent the mean \pm standard deviation of three independent experiments. "P<0.05. CDK, cyclin-dependent kinase; NC, negative control; in, inhibitor; siRNA, small interfering RNA; miRNA, microRNA. 
Recent studies revealed that miR-143, as a tumor suppressor, targeted the 3'-UTR of KRAS, c-Myc and GLI family zinc finger 3, which regulate cell DNA damage repair, cell adhesion ability and cell migration in NPC, respectively $(11,24,25)$. In the present study, CDK6 was identified to be a direct target of miR-143, which downregulates its expression. These results support the hypothesis that miR-143 regulates cell proliferation by targeting the cell cycle regulator CDK6 and affecting cell function. Furthermore, consistent with previous studies, CDK6 regulation by specific miRNAs is essential in tumor development and progression.

It has also been shown that cell cycle inhibitors block the proliferation of adult stem cells in multiple tissue types. For example, $\mathrm{p} 21^{\mathrm{Cip} 1}$ and $\mathrm{p} 27^{\mathrm{Kip} 1}$ may control self-renewal of neural, intestinal and hematopoietic progenitors $(26,27)$. Consistent with those studies, the present study demonstrated that ectopic miR-143 expression inhibited cyclin D1 expression and induced $\mathrm{p} 21^{\mathrm{Cip} 1}$ and $\mathrm{p} 27^{\mathrm{Kip} 1}$ expression.

In summary, the present study reports for the first time an important link between miR-143 and CDK6 in NPC progression. miR-143 regulates NPC cell proliferation by downregulating CDK6. These results suggest that miR-143 is an anti-oncogene and may represent a potential therapeutic target for NPC.

\section{Acknowledgements}

The present study was supported by a grant from the Science and Technology Planning Project of Guangdong Province (Guangzhou, China; grant no. 2012B031800480).

\section{References}

1. Chen HK, Liu XQ, Lin J, Chen TY, Feng QS and Zeng YX: Mutation analysis of KLF6 gene in human nasopharyngeal carcinomas. Ai Zheng 21: 1047-1050, 2002 (In Chinese).

2. Lo KW and Huang DP: Genetic and epigenetic changes in nasopharyngeal carcinoma. Semin Cancer Biol 12: 451-462, 2002.

3. Cheung ST, Huang DP, Hui AB, Lo KW, Ko CW, Tsang YS, Wong N, Whitney BM and Lee JC: Nasopharyngeal carcinoma cell line (C666-1) consistently harbouring Epstein-Barr virus. Int J Cancer 83: 121-126, 1999.

4. Macfarlane LA and Murphy PR: MicroRNA: Biogenesis, function and role in cancer. Curr Genomics 11: 537-561, 2010.

5. Calin GA and Croce CM: MicroRNA signatures in human cancers. Nat Rev Cancer 6: 857-866, 2006.

6. Farazi TA, Hoell JI, Morozov P and Tuschl T: MicroRNAs in human cancer. Adv Exp Med Biol 774: 1-20, 2013.

7. Kim VN and Nam JW: Genomics of microRNA. Trends Genet 22: 165-173, 2006.

8. Olena AF and Patton JG: Genomic organization of microRNAs. J Cell Physiol 222: 540-545, 2010.

9. Godlewski J, Nowicki MO, Bronisz A, Williams S, Otsuki A, Nuovo G, Raychaudhury A, Newton HB, Chiocca EA and Lawler S: Targeting of the Bmi-1 oncogene/stem cell renewal factor by microRNA-128 inhibits glioma proliferation and self-renewal. Cancer Res 68: 9125-9130, 2008.
10. Cho WC: OncomiRs: The discovery and progress of microRNAs in cancers. Mol Cancer 6: 60, 2007.

11. Zhong W, He B, Zhu C, Xiao L, Zhou S and Peng X: MiR-143 inhibits migration of human nasopharyngeal carcinoma cells by negatively regulating GLI3 gene. Nan Fang Yi Ke Da Xue Xue Bao 33: 1057-1061, 2013 (In Chinese).

12. Peng X, Guo W, Liu T, Wang X, Tu X, Xiong D, Chen S, Lai Y, Du H, Chen G, et al: Identification of miRs-143 and -145 that is associated with bone metastasis of prostate cancer and involved in the regulation of EMT. PLoS One 6: e20341, 2011.

13. Wang CJ, Zhou ZG, Wang L, Yang L, Zhou B, Gu J, Chen HY and Sun XF: Clinicopathological significance of microRNA-31, -143 and -145 expression in colorectal cancer. Dis Markers 26: 27-34, 2009.

14. Takagi T, Iio A, Nakagawa Y, Naoe T, Tanigawa N and Akao Y: Decreased expression of microRNA-143 and -145 in human gastric cancers. Oncology 77: 12-21, 2009.

15. Noguchi S, Mori T, Hoshino Y, Maruo K, Yamada N, Kitade Y, Naoe T and Akao Y: MicroRNA-143 functions as a tumor suppressor in human bladder cancer T24 cells. Cancer Lett 307: 211-220, 2011.

16. Deftereos G, Corrie SR, Feng Q, Morihara J, Stern J, Hawes SE and Kiviat NB: Expression of mir-21 and mir-143 in cervical specimens ranging from histologically normal through to invasive cervical cancer. PLoS One 6: e28423, 2011.

17. Medema RH, Kops GJ, Bos JL and Burgering BM: AFX-like Forkhead transcription factors mediate cell-cycle regulation by Ras and PKB through p27kip1. Nature 404: 782-787, 2000.

18. Kozar K and Sicinski P: Cell cycle progression without cyclin D-CDK4 and cyclin D-CDK6 complexes. Cell Cycle 4: 388-391, 2005.

19. Malumbres M and Barbacid M: Cell cycle, CDKs and cancer: A changing paradigm. Nat Rev Cancer 9: 153-166, 2009.

20. Wang X, Wu J, Lin Y, Zhu Y, Xu X, Xu X, Liang Z, Li S, Hu Z, Zheng X and Xie L: MicroRNA-320c inhibits tumorous behaviors of bladder cancer by targeting Cyclin-dependent kinase 6. J Exp Clin Cancer Res 33: 69, 2014

21. Zhang J, Wang L, Li B, Huo M, Mu M, Liu J and Han J: miR-145 downregulates the expression of cyclin-dependent kinase 6 in human cervical carcinoma cells. Exp Ther Med 8: 591-594, 2014.

22. Kikkawa N, Kinoshita T, Nohata N, Hanazawa T, Yamamoto N, Fukumoto I, Chiyomaru T, Enokida H, Nakagawa M, Okamoto Y and Seki N: microRNA-504 inhibits cancer cell proliferation via targeting CDK6 in hypopharyngeal squamous cell carcinoma. Int J Oncol 44: 2085-2092, 2014.

23. Honeywell DR, Cabrita MA, Zhao H, Dimitroulakos J and Addison CL: miR-105 inhibits prostate tumour growth by suppressing CDK6 levels. PLoS One 8: e70515, 2013.

24. Xu YF, Li YQ, Guo R, He QM, Ren XY, Tang XR, Jia WH, Kang TB, Zeng MS, Sun Y, et al: Identification of miR-143 as a tumour suppressor in nasopharyngeal carcinoma based on microRNA expression profiling. Int J Biochem Cell Biol 61: 120-128, 2015.

25. Wang W, Wu S, Shi Y, Miao Y, Luo X, Ji M, Yao K and He J: c-MYB regulates cell growth and DNA damage repair through modulating MiR-143. FEBS Lett 589: 555-564, 2015.

26. Choudhury AR, Ju Z, Djojosubroto MW, Schienke A, Lechel A, Schaetzlein S, Jiang H, Stepczynska A, Wang C, Buer J, et al: Cdknla deletion improves stem cell function and lifespan of mice with dysfunctional telomeres without accelerating cancer formation. Nat Genet 39: 99-105, 2007.

27. Fasano CA, Dimos JT, Ivanova NB, Lowry N, Lemischka IR and Temple S: shRNA knockdown of Bmi-1 reveals a critical role for p21-Rb pathway in NSC self-renewal during development. Cell Stem Cell 1: 87-99, 2007. 